\begin{tabular}{|c|c|c|c|}
\hline \multirow{2}{*}{$\begin{array}{r}\text { Case Reports in } \\
\text { Gastroenterology }\end{array}$} & \multicolumn{2}{|c|}{ Case Rep Gastroenterol 2015;9:291-295 } & \multirow[b]{2}{*}{$\begin{array}{l}\text { Karger } \\
\text { Open access }\end{array}$} \\
\hline & $\begin{array}{l}\text { DOI: } 10.1159 / 000438745 \\
\text { Publisned onine: August 7, } 2015\end{array}$ & $\begin{array}{l}\text { (C) } 2015 \text { S. Karger AG, Basel } \\
1662-0631 / 15 / 0092-0291 \$ 39.50 / 0 \\
\text { www.karger.com/crg }\end{array}$ & \\
\hline & \multicolumn{2}{|c|}{$\begin{array}{l}\text { This is an Open Access article licensed under the terms of the Creative Commons } \\
\text { Attribution-NonCommercial } 3.0 \text { Unported license (CC BY-NC) (www.karger.com/OA } \\
\text { license), applicable to the online version of the article only. Distribution permitted for non } \\
\text { commercial purposes only. }\end{array}$} & \\
\hline
\end{tabular}

\title{
Resolution of Severe Ulcerative Colitis with the Specific Carbohydrate Diet
}

\author{
Birgit N. Khandalavala Maya C. Nirmalraj \\ Department of Family Medicine, University of Nebraska Medical Center, \\ Omaha, Nebr., USA
}

\section{Key Words}

Ulcerative colitis · Inflammatory bowel disease · Dietary therapy

\begin{abstract}
A 73-year-old female of Asian origin was diagnosed with ulcerative colitis (UC) after initial gastrointestinal symptoms of abdominal pain and bloody diarrhea. She had a relatively benign course over the subsequent 12 years. In 2009, she had increased left-sided abdominal pain, bloody diarrhea and progressive weight loss, due to a severe exacerbation. In spite of a variety of standard treatments, her condition continued to decline with a significant impact on normal life and functioning. In December of 2010, repeat colonoscopy and microscopy confirmed pancolitis, without diverticulitis. The Specific Carbohydrate Diet (SCD) was initiated due to failure of conventional therapies. Following this highly restricted diet, within a period of 3-6 months, improvement was noted, and within a year, no abdominal pain or diarrhea were present, and she returned to her baseline functioning and career. Two years later, repeat colonoscopy showed resolution of the pancolitis, confirmed with microscopic evaluation. Successful use of the SCD in children with UC has been documented. We describe previously unreported, highly beneficial results with both symptomatic and clinical improvement and complete remission of UC in an adult female with the SCD.

(c) 2015 S. Karger AG, Basel
\end{abstract}

\section{Introduction}

Inflammatory bowel disease (IBD) includes 2 main conditions: ulcerative colitis (UC) and Crohn disease. UC is a chronic inflammatory disorder characterized by inflammation of the mucosal layer of the colon [1]. Its pathogenesis is not fully understood, but studies have

KARGER 125/s $\quad \begin{aligned} & \text { Birgit Khandalavala, MD } \\ & \text { UNMC Department of Family Medicine } \\ & \text { 983075 Nebraska Medical Center } \\ & \text { Omaha, NE 68198-3075 (USA) } \\ & \text { E-Mail birgit.khandalavala@unmc.edu }\end{aligned}$


Khandalavala and Nirmalraj: Resolution of Severe Ulcerative Colitis with the Specific Carbohydrate Diet

shown that an unknown agent activates immune cells [2]. The traditional management consists of immunosuppressive agents, antidiarrheal agents and sulfasalazine [2].

Food antigens have been suspected to elicit an immunologic response in the development of UC [2]. Studies have been conflicting regarding particular diets that may aggravate IBD. Potential dietary risk factors include sensitivity to dairy, wheat, refined sugar, fiber and a typical 'Western' diet [2]. Several diets have been effective without conclusive scientific testing.

The Specific Carbohydrate Diet (SCD) was conceived and tested by Dr. Sidney Haas and Elaine Gottschall [3]. The SCD is based on the theory that gut microbiome dysbiosis is associated with IBD [3]. Thus, by making dietary changes, the intestinal flora can potentially be altered, resulting in improvement. The diet incorporates a dual action of not only elimination of factors presumably contributing to the dysbiosis, but including restoration of the disrupted gut microbiome.

Allowed foods are based on the molecular structure of the carbohydrates [3]. Monosaccharides are simple carbohydrates, with a single structure facilitating easier absorption and digestion [3]. Foods that include monosaccharides are fruit, some vegetables, honey and yogurt. Most disaccharides, polysaccharides and starches are avoided as they are more complex, less easily digested and considered to aggravate intestinal inflammation. Fermented yogurt is a vital component of the SCD, promoting the replenishment of presumed healthy intestinal flora [3].

We report the successful remission of disease activity in a single adult patient with known IBD with the SCD. This case report, to the best of our knowledge, is the first documented instance in the literature in an adult with UC.

\section{Case Report}

A 73-year-old female of Asian origin with a long-standing history of UC presented with the most severe and persistent flare of her disease. She had received the initial diagnosis of UC in 1997 when she developed abdominal pain and rectal bleeding with loose mucous stools and underwent a diagnostic colonoscopy with a gastroenterologist. She responded to mesalamine (Asacol) given for a period of 6 weeks, which was later discontinued by the patient.

For the next 12 years, she was relatively stable with standard American diet recommendations and did not exclude wheat and dairy or focused on the inclusion of particular fermented foods. The patient incorporated powdered ayurvedic and homeopathic oral treatment, which included some spices like nutmeg but did not contain any fresh or fermented products. In the winter of 2009, she experienced intermittent burning and shooting pain predominately in the left lower quadrant of the abdomen. Pain in the right lower quadrant was present often concomitantly, and on occasion, was present in the absence of the leftsided pain. Episodes of rectal bleeding and mucoid loose stools progressed over the duration of the next year. No fever or skin rashes were present at any time. Decreased appetite and overall weight loss of 7 pounds occurred within the 12 months. She was admitted at assorted facilities and underwent consultations with various gastroenterologists and other specialists, with increasing fatigue and finally, an inability to continue working.

The differential diagnosis included diverticulitis and tuberculosis among others, all of which were excluded. Multiple, episodic and varied therapies including corticosteroids and mesalamine were prescribed, with limited efficacy and poor tolerance. In December of 2010, her weight was 128 pounds, and she appeared pale, fatigued and chronically ill. She had not 
Khandalavala and Nirmalraj: Resolution of Severe Ulcerative Colitis with the Specific Carbohydrate Diet

been able to function as a physician and was in constant abdominal pain with unremitting bloody diarrhea. Hemoglobin of $10.5 \mathrm{~g} / \mathrm{dl}$ and mild hypokalemia of $3.2 \mathrm{mEq} / \mathrm{l}$ was seen with no elevation of the liver enzymes and normal renal function. White blood cell count was normal. Colonoscopy was performed and revealed pancolitis (fig. 1) with sigmoid colonic diverticula but no evidence of diverticulitis or neoplastic changes. Mild to moderate IBD consistent with chronic UC was noted with patchy areas through the cecum, ascending, transverse, descending, and sigmoid and rectum, and some difficulty entering the ileocecal valve. The colonic mucosa revealed friability, multiple tiny ulcers and mucosal edema. Biopsies were obtained throughout the colon and confirmed UC.

Since the patient had persistent and progressive symptoms, with worsening clinical parameters, given the failure of previous conventional therapy, the SCD was recommended and initiated using Elaine Gottschall's book as the guide [3]. She proceeded to completely exclude wheat, soy, barley, corn and limited rice. No other dairy products other than daily yoghurt were included. Sugar was limited to honey. No starchy vegetables were eaten and potatoes were eliminated. She ate mostly fish, lean meat, certain fruit and restricted nonstarchy vegetables.

Following this highly restricted diet, within a period of 3-6 months, the patient started noticing improvement with decreased frequency as well as firmer consistency of the stools, blood in the stools was absent and abdominal pain resolved. Within 6 months, she was able to return to her normal activities and career as a physician. Weakness and fatigue dissipated, while weight remained stable, without any regain. Anemia was found to have resolved, and hemoglobin was in the normal range. She continued with strict adherence to the diet due to the remarkable recovery, with dissipation of all of her symptoms over the next 18 months.

Subsequent colonoscopy done 2 years after starting the diet was conducted in December 2012, and findings on endoscopy showed a remarkable absence of any inflammation (fig. 2). Biopsies obtained simultaneously confirmed the complete remission of UC with no inflammatory activity present. Since this time, she has noted that accidental consumption of wheat, peppers and other nonapproved SCD foods caused acute flare-ups, and the prompt elimination of these foods resulted in improvement of symptoms within a few days. She has not required hospitalization or additional therapy for UC since the institution of the diet and continues to be essentially in remission from the IBD. A few episodes of self-limited diverticulitis have been noted since.

\section{Discussion}

UC is known to have a bimodal peak in the age groups of $15-30$ and $60-80$ years [4]. In both children and adults, there are numerous diets and complementary therapies that have been used. However, at this time, there is little consensus among the complementary therapies. While gluten-free diets have been used for IBD in adults, the SCD has been found to be successful in a small retrospective study of 7 children [5]. Our case demonstrated unprecedented healing of recalcitrant and remitting UC, following institution of the SCD, in an adult.

This case study demonstrates the easy tolerability and lack of significant side effects of the SCD. Confirmation of healing with endoscopy and microscopy validates the clinical improvement experienced by this patient. The diet requirements were relatively simple to incorporate though highly restrictive and are similar to those undertaken with celiac disease but included a prominent component of fermented dairy. A major strength of this case study is the ease of translation into clinical practice by busy clinicians, without the need for additional resources. 
Khandalavala and Nirmalraj: Resolution of Severe Ulcerative Colitis with the Specific Carbohydrate Diet

One of the limitations of this case study was the absence of definitive serological testing for celiac disease prior to the institution of the diet to determine occult gluten sensitivity. A further limitation of the dietary intervention are the restricted choices available outside of the home and the difficulty with absolute long-term adherence.

However, similar to patients with celiac disease, the food choices for patients on restricted diets has been steadily increasing in the United States, with gluten-free options having had a 63\% increase in sales from 2012 to 2014 [6]. We anticipate that with greater promulgation of elimination diets, it will be more conducive to adhere outside of the home environment.

We would recommend that physicians and dieticians who are involved with gastrointestinal diseases look into alternative therapies, not only for patients with celiac disease but potentially also for those with IBD and UC. Further testing for specific food allergens and gut microbiome dysfunction could be helpful. Our suggestion is that future studies incorporate genetic markers and serological testing prior to making the changes.

The SCD has been used anecdotally for UC; however, the evidence of its effectiveness has not been conclusive. We report complete healing of UC in a patient who had failed conventional therapies within a 2-year period. The use of the SCD for UC in patients who are able to make sustainable dietary changes should be considered more often.

\section{Disclosure Statement}

No financial support has been received for the work reported.

\section{References}

$\checkmark 1$ Gasche C, Scholmeric J, Brynskov J, et al: A simple classification of Crohn's disease: report of the Working Party for the World Congresses of Gastroenterology, Vienna 1998. Inflamm Bowel Dis 2000;6:8.

2 Peppercorn MA: Definition, epidemiology, and risk factors in inflammatory bowel disease; in Grover S (ed): UptoDate. 2015. http://www.uptodate.com/contents/definition-epidemiology-and-risk-factors-ininflammatory-bowel-disease.

3 Gottschall E: Breaking the Vicious Cycle. Kirkton, Kirkton Press, 1994.

4 Harrison T, Longo D: Harrison's Manual of Medicine. New York, McGraw-Hill Medical, 2013.

5 Suskind DL, Wahbeh G, Gregory N, Vendettuoli H, Christie D: Nutritional therapy in pediatric Crohn disease: the specific carbohydrate diet. J Pediatr Gastroenterol Nutr 2014;58:87-91.

6 Gluten-Free Foods Surge 63\% in Last Two Years. Mintel Group Ltd. 2014. http://www.mintel.com/presscentre/food-and-drink/gluten-free-foods-surge-63-percent.

This case report was previously presented as a poster at the Experimental Biology 2015 conference. The abstract of this case report was previously published for the Experimental Biology 2015 conference in their corresponding journal [FASEB J 2015;29:912.7]. 


\section{Case Reports in \\ Gastroenterology}

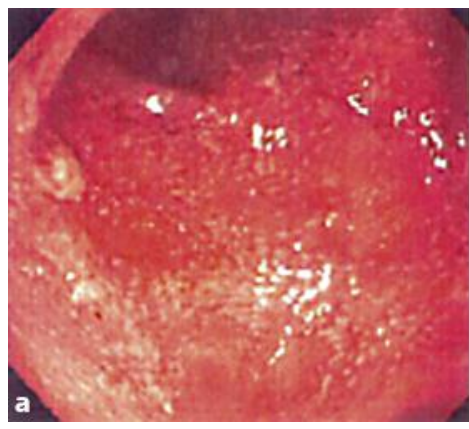

\begin{tabular}{l|l}
\hline \multicolumn{2}{l|}{ Case Rep Gastroenterol 2015;9:291-295 } \\
\hline DOI: $10.1159 / 000438745$ & $\begin{array}{l}\text { C } 2015 \text { S. Karger AG, Basel } \\
\text { www.karger.com/crg }\end{array}$ \\
\hline
\end{tabular}

Khandalavala and Nirmalraj: Resolution of Severe Ulcerative Colitis with the Specific Carbohydrate Diet

Fig. 1. Terminal ileum (a, b) and cecum (c). Endoscopic photographs of the sigmoid and left side of the colon demonstrating active mucosal inflammation taken prior to institution of the SCD in December 2010, following 1 year of an acute exacerbation of UC in a 73-year-old patient. Pancolitis was noted on complete colonoscopy.
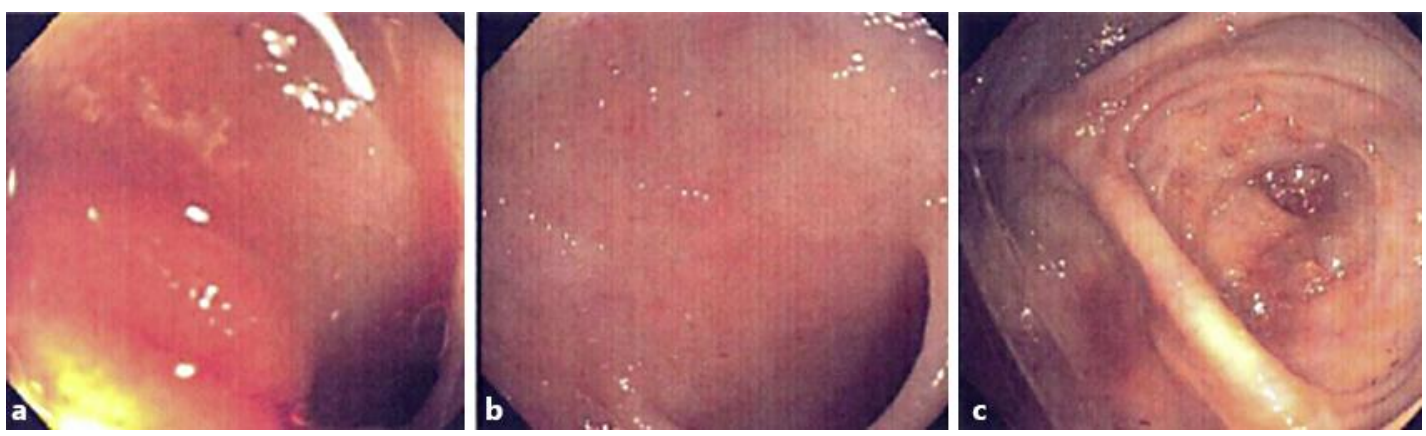

Fig. 2. Terminal ileum (a, b) and cecum (c) demonstrating normal colonic mucosa with no inflammation after 2 years of the SCD (December 2012). Complete colonoscopy confirmed resolution in all segments of the colon. 